\title{
Fixed point theorems for hybrid contraction without continuity
}

\author{
U. C. Gairola, Ram Krishan * \\ Department of Mathematics, H. N. B. Garhwal University,Pauri Campus, Pauri Garhwal-246001, Uttarakhand, India \\ *Corresponding author E-mail: ram.krishan976@gmail.com
}

Copyright (C)2015 U. C. Gairola and Ram Krishan. This is an open access article distributed under the Creative Commons Attribution License, which permits unrestricted use, distribution, and reproduction in any medium, provided the original work is properly cited.

\begin{abstract}
In this paper we establish a coincidence and fixed point theorems for hybrid contraction under generalized weakly contractive condition by using the concept of (IT)-commutativity in a complete metric space without appeal to continuity of mappings. Our results extend and generalize the results of Choudhury et al. [6] and others.
\end{abstract}

Keywords: Coincidence Point, Fixed Point, Control Function, Weak Contraction.

\section{Introduction}

Study of fixed point theorem for multi-valued mappings was initiated by Nadler [22]. Subsequently a number of fixed point theorems in metric space have been proved for multi-valued mapping satisfying contractive type conditions (see, for instance [8], [9], [18], [20], [32] and references therein). Later on the study of hybrid fixed point theory for nonlinear single-valued and multi-valued mappings is a new development in the domain of contractive type multi-valued theory ( see, for instance [4], [5], [12], [17], [21], [24], [28], [29], [30], [31], [33], [34] and references therein). On the other hand Alber and Guerre-Delabriere [3], defined weakly contractive mappings on a Hilbert space and established a fixed point theorem for such a mappings. Subsequently Rhoades [26] use the notion of weakly contractive mappings and obtained a fixed point theorem in complete metric space.

Afterward, weak contraction and function satisfying weak contractive type inequalities have been considered in a large number of papers, (see, for instance [1], [2], [6], [7], [11], [25] and references therein).

In this paper we will establish a fixed point theorems under generalized weak contractive condition for a pair of multi-valued and single-valued mappings by using the concept of (IT)-commutativity of mappings in complete metric space without appeal to continuity of mappings. Our results extend and generalize the results of Choudhury et al. [6] and others.

\section{Preliminary notes}

Let $(X, d)$ be a metric space. Following [22], we define $C L(X)=\{A: A$ is a non-empty closed subset of $X\}$. $C B(X)=\{A: A$ is a non-empty closed and bounded subset of $X\}$. $C(X)=\{A: A$ is a non-empty compact subset of $X\}$. 
$B N(X)=\{A: A$ is a non-empty bounded subset of $X\}$.

For non-empty subsets $A$ and $B$ of $X$, and $x \in X$,

$D(A, B)=\inf \{d(a, b): a \in A, b \in B\}$.

$H(A, B)=\max [\sup \{D(a, B): a \in A\}, \sup \{D(A, b): b \in B\}]$.

$d(x, A)=\inf \{d(x, a): a \in A\}$.

$\delta(A, B)=\sup \{d(a, b): a \in A, b \in B\}$.

Following Hadžić-Gajić [13] and Pant [23], Singh-Mishra [30] introduced the notion of R-weak commutativity of a hybrid pair of single-valued and multi-valued mappings.

Definition 2.1. [30] : Let $(X, d)$ be a metric space. The mappings $f: X \rightarrow X$ and $T: X \rightarrow C L(X)$ are pointwise R-weakly commuting on $X$ if given $x \in X$ and $f x \in X$, there exists $R>0$ such that

$d(f y, T f x) \leq R d(T x, f x) \quad$ for each $y \in X \cap T x$.

Mappings $f$ and $T$ will be called R-weakly commuting on $X$ if for each $x \in X$ and $(A)$ hold for some $R>0$.

Following Jungck [15] and Jungck-Rhoades [16], we have the following definition.

Definition 2.2. The mappings $f: X \rightarrow X$ and $T: X \rightarrow C L(X)$ are weakly compatible if they commute at their coincidence points, that is, $T f x=f T x$ whenever $f x \in T x$.

Following Itoh-Takahashi [14] and Singh-Mishra [30], we have the following definition of (IT)-commutativity.

Definition 2.3. The mappings $f: X \rightarrow X$ and $T: X \rightarrow C L(X)$ are commuting at a point $x \in X$ if $f T x \subset T f x$. $f$ and $T$ are commuting on $X$ if they are commuting at each point $x \in X$.

The above commutativity is called Itoh-Takahashi commutativity or simply (IT)-commutativity (see, [30]).

The following example shows that (IT)-commutativity of $f$ and $T$ at a coincidence point is indeed more general than their weak compatibility at the same point.

Example 2.4. [30] : Let $X=[0, \infty)$ with the usual metric $d$ and $f x=4 x, T x=[3+x, \infty), x \in X$. Then $f 1 \in T 1, f T 1 \subset T f 1$, and $f, T$ are (IT)-commuting at $x=1$. The inequality $(A)$ is also satisfied for $x=1$ and $f, T$ are R-weakly commuting at $x=1$. Notice that $f, T$ are not weakly compatible since $f T 1 \neq T f 1$.

Notation $C(f, T)$ will stand for the set of coincidence points of the mappings $f$ and $T$, that is, $C(f, T)=\{z$ : $f z \in T z\}$.

Following Rhoades [26], we have the following definition.

Definition 2.5. [26] : A mapping $f: X \rightarrow X$, where $(X, d)$ is a metric space, is said to be weakly contractive if for $x, y \in X$

$d(f x, f y) \leq d(x, y)-\phi(d(x, y))$

where $\phi:[0, \infty) \rightarrow[0, \infty)$ is a continuous and non-decreasing function such that $\phi(t)=0$ if and only if $t=0$. If one takes $\phi(t)=(1-k) t$, where $0<k<1$, a weak contraction reduces to a Banach contraction.

In (1976-77), Delbosco [10] and Skof [35] have established fixed point theorem for self mappings of complete metric space by altering the distances between the points and subsequently, Khan et al. [19] generalized the notion of altering distance between the point.

Definition 2.6. ([10] see also [35]): A function $\psi:[0, \infty) \rightarrow[0, \infty)$ is called an altering distance function if the following properties are satisfied:

I. $\psi$ is monotone increasing and continuous,

II. $\psi(t)=0$ if and only if $t=0$.

Recently Choudhury et al. [6] defined generalized weak contraction and proved the following theorem.

Definition 2.7. [6] : Let $(X, d)$ be a metric space, $f$ a self mapping of $X$. We shall call $f$ a generalized weakly contractive mapping if for all $x, y \in X$

$$
\begin{aligned}
\psi(d(f x, f y)) \leq & \psi\left(\max \left\{d(x, y), d(x, f x), d(y, f y), \frac{1}{2}[d(x, f y)+d(y, f x)]\right\}\right) \\
& -\phi(\max \{d(x, y), d(y, f y)\}),
\end{aligned}
$$


where $\psi$ is an altering distance function and $\phi:[0, \infty) \rightarrow[0, \infty)$ is a continuous function with $\phi(t)=0$ if and only if $t=0$.

Theorem 2.8. [6] : Let $(X, d)$ be a complete metric space, and let $f: X \rightarrow X$ be such that

$$
\begin{aligned}
\psi(d(f x, f y)) \leq & \psi\left(\max \left\{d(x, y), d(x, f x), d(y, f y), \frac{1}{2}[d(x, f y)+d(y, f x)]\right\}\right) \\
& -\phi(\max \{d(x, y), d(y, f y)\}),
\end{aligned}
$$

for some $\phi$ and $\psi$ defined as in Definition 2.5 and 2.6. Then $f$ has a unique fixed point.

\section{Main results}

Now we state our main result.

Theorem 3.1. Let $(X, d)$ be a complete metric space. Let $S, T: X \rightarrow C(X)$ be two multi-valued mappings and $f: X \rightarrow X$ be a self mapping such that for all $x, y \in X$

$S(X) \cup T(X) \subset f(X)$

$f(X)$ is closed

$\psi(H(S x, T y)) \leq \psi(M(x, y))-\phi(m(x, y))$,

where

$M(x, y)=\max \left\{d(f x, f y), D(f x, S x), D(f y, T y), \frac{1}{2}[D(f x, T y)+D(f y, S x)]\right\}$

and

$m(x, y)=\max \{d(f x, f y), D(f x, S x), D(f y, T y)\}$,

where $\phi:[0, \infty) \rightarrow[0, \infty)$ is a continuous function with $\phi(t)=0$ if and only if $t=0$ and $\psi:[0, \infty) \rightarrow[0, \infty)$ is an altering distance function. Then $S, f$ and $T, f$ have a coincidence point. Further $S$ and $f$ have a common fixed point $f u$ provided $f f u=f u$ and $S, f$ are (IT)-commuting at $u \in C(S, f)$ and if $T$ and $f$ have a common fixed point $f u$ provided $f f u=f u$ and $T, f$ are (IT)-commuting at $u \in C(T, f)$. Then $S, T$ and $f$ have a common fixed point.

Proof. Let $x_{0}$ be an arbitrary point in $X$. We shall construct sequences $\left\{x_{n}\right\}$ and $\left\{y_{n}\right\}$ as follows. Since $S(X) \cup T(X) \subset f(X)$, we can choose points $x_{1}, x_{2}$ in $X$ such that

$y_{1}=f x_{1} \in S x_{0}$

and

$y_{2}=f x_{2} \in T x_{1}$.

In view of the Remark of Nadler [22, page 480], we have the following

$d\left(f x_{1}, f x_{2}\right) \leq H\left(S x_{0}, T x_{1}\right)$.

So

$\psi\left(d\left(y_{1}, y_{2}\right)\right) \leq \psi\left(H\left(S x_{0}, T x_{1}\right)\right) \leq \psi\left(M\left(x_{0}, x_{1}\right)\right)-\phi\left(m\left(x_{0}, x_{1}\right)\right)$.

Similarly choose $x_{3}, x_{4}$ in $X$ such that

$y_{3}=f x_{3} \in S x_{2}$

and

$y_{4}=f x_{4} \in T x_{3}$. 
Again in view of the Remark of Nadler [22, page 480], we have the following $d\left(f x_{3}, f x_{4}\right) \leq H\left(S x_{2}, T x_{3}\right)$.

So

$\psi\left(d\left(y_{3}, y_{4}\right)\right) \leq \psi\left(H\left(S x_{2}, T x_{3}\right)\right) \leq \psi\left(M\left(x_{2}, x_{3}\right)\right)-\phi\left(m\left(x_{2}, x_{3}\right)\right)$.

We continue this process to obtain a sequence $\left\{y_{n}\right\}$ in $X$ such that

$y_{2 n+1}=f x_{2 n+1} \in S x_{2 n}$

and

$y_{2 n+2}=f x_{2 n+2} \in T x_{2 n+1}$, for all $n=0,1,2,3 \ldots$.

If there exists a positive integer $2 n$ such that $y_{2 n+1}=y_{2 n+2}$, then $y_{2 n+1}$ is a coincidence point of $f$ and $T$. A similar conclusion holds if $y_{2 n+2}=y_{2 n+3}$, for some $n$, then $f$ and $S$ have a coincidence point. Therefore we may assume that $y_{n} \neq y_{n+1}$, for all $n \geq 0$. Then we have the following

$$
\begin{aligned}
\psi\left(d\left(y_{2 n+1}, y_{2 n+2}\right)\right) \leq & \psi\left(H\left(S x_{2 n}, T x_{2 n+1}\right)\right) \leq \psi\left(M\left(x_{2 n}, x_{2 n+1}\right)\right)-\phi\left(m\left(x_{2 n}, x_{2 n+1}\right)\right) \\
\leq & \psi\left(\max \left\{\begin{array}{c}
d\left(f x_{2 n}, f x_{2 n+1}\right), D\left(f x_{2 n}, S x_{2 n}\right), D\left(f x_{2 n+1}, T x_{2 n+1}\right), \\
\frac{1}{2}\left[D\left(f x_{2 n}, T x_{2 n+1}\right)+D\left(f x_{2 n+1}, S x_{2 n}\right)\right]
\end{array}\right\}\right) \\
& -\phi\left(\max \left\{d\left(f x_{2 n}, f x_{2 n+1}\right), D\left(f x_{2 n}, S x_{2 n}\right), D\left(f x_{2 n+1}, T x_{2 n+1}\right)\right\}\right) \\
\leq & \psi\left(\max \left\{\begin{array}{c}
d\left(y_{2 n}, y_{2 n+1}\right), d\left(y_{2 n}, y_{2 n+1}\right), d\left(y_{2 n+1}, y_{2 n+2}\right), \\
\frac{1}{2}\left[d\left(y_{2 n}, y_{2 n+2}\right)+d\left(y_{2 n+1}, y_{2 n+1}\right)\right]
\end{array}\right\}\right) \\
& -\phi\left(\max \left\{d\left(y_{2 n}, y_{2 n+1}\right), D\left(f x_{2 n}, S x_{2 n}\right), D\left(f x_{2 n+1}, T x_{2 n+1}\right)\right\}\right) .
\end{aligned}
$$

Since $\frac{1}{2}\left[d\left(y_{2 n}, y_{2 n+2}\right)\right] \leq \max \left\{d\left(y_{2 n}, y_{2 n+1}\right), d\left(y_{2 n+1}, y_{2 n+2}\right)\right\}$, it follows that

$$
\begin{aligned}
\psi\left(d\left(y_{2 n+1}, y_{2 n+2}\right)\right) \leq & \psi\left(\max \left\{d\left(y_{2 n}, y_{2 n+1}\right), d\left(y_{2 n+1}, y_{2 n+2}\right)\right\}\right) \\
& -\phi\left(\max \left\{d\left(y_{2 n}, y_{2 n+1}\right), D\left(f x_{2 n}, S x_{2 n}\right), D\left(f x_{2 n+1}, T x_{2 n+1}\right)\right\}\right) .
\end{aligned}
$$

Suppose that $d\left(y_{2 n}, y_{2 n+1}\right) \leq d\left(y_{2 n+1}, y_{2 n+2}\right)$ and $d\left(y_{2 n}, y_{2 n+1}\right) \leq D\left(f x_{2 n}, S x_{2 n}\right)$, for some positive integer $n$. Then from (6), we have

$\psi\left(d\left(y_{2 n+1}, y_{2 n+2}\right)\right) \leq \psi\left(d\left(y_{2 n+1}, y_{2 n+2}\right)\right)-\phi\left(D\left(f x_{2 n}, S x_{2 n}\right)\right)$,

that is,$\phi\left(D\left(f x_{2 n}, S x_{2 n}\right)\right) \leq 0$, which implies that $D\left(f x_{2 n}, S x_{2 n}\right)=0$, that is $f x_{2 n} \in S x_{2 n}$ or $y_{2 n} \in S x_{2 n}$ contradicting the formation of the sequence. Therefore $D\left(f x_{2 n}, S x_{2 n}\right)<d\left(y_{2 n}, y_{2 n+1}\right)$, for all $n \geq 0$. Again suppose that $d\left(y_{2 n}, y_{2 n+1}\right) \leq d\left(y_{2 n+1}, y_{2 n+2}\right)$ and $d\left(y_{2 n}, y_{2 n+1}\right) \leq D\left(f x_{2 n+1}, T x_{2 n+1}\right)$, for some positive integer $n$. Then from (6), we have

$\psi\left(d\left(y_{2 n+1}, y_{2 n+2}\right)\right) \leq \psi\left(d\left(y_{2 n+1}, y_{2 n+2}\right)\right)-\phi\left(D\left(f x_{2 n+1}, T x_{2 n+1}\right)\right)$,

that is, $\phi\left(D\left(f x_{2 n+1}, T x_{2 n+1}\right)\right) \leq 0$, which implies that $D\left(f x_{2 n+1}, T x_{2 n+1}\right)=0$, that is $f x_{2 n+1} \in T x_{2 n+1}$ or $y_{2 n+1} \in T x_{2 n+1}$ contradicting the formation of the sequence.

Therefore $D\left(f x_{2 n+1}, T x_{2 n+1}\right)<d\left(y_{2 n}, y_{2 n+1}\right)$, for all $n \geq 0$.

Now

$$
\begin{aligned}
\psi\left(d\left(y_{2 n+3}, y_{2 n+2}\right)\right) \leq & \psi\left(H\left(S x_{2 n+2}, T x_{2 n+1}\right)\right) \leq \psi\left(M\left(x_{2 n+2}, x_{2 n+1}\right)\right)-\phi\left(m\left(x_{2 n+2}, x_{2 n+1}\right)\right) \\
\leq & \psi\left(\max \left\{\begin{array}{c}
d\left(f x_{2 n+2}, f x_{2 n+1}\right), D\left(f x_{2 n+2}, S x_{2 n+2}\right), D\left(f x_{2 n+1}, T x_{2 n+1}\right), \\
\frac{1}{2}\left[D\left(f x_{2 n+2}, T x_{2 n+1}\right)+D\left(f x_{2 n+1}, S x_{2 n+2}\right)\right]
\end{array}\right\}\right) \\
& -\phi\left(\max \left\{d\left(f x_{2 n+2}, f x_{2 n+1}\right), D\left(f x_{2 n+2}, S x_{2 n+2}\right), D\left(f x_{2 n+1}, T x_{2 n+1}\right)\right\}\right) \\
\leq & \psi\left(\max \left\{\begin{array}{c}
d\left(y_{2 n+2}, y_{2 n+1}\right), d\left(y_{2 n+2}, y_{2 n+3}\right), d\left(y_{2 n+1}, y_{2 n+2}\right), \\
\frac{1}{2}\left[d\left(y_{2 n+2}, y_{2 n+2}\right)+d\left(y_{2 n+1}, y_{2 n+3}\right)\right]
\end{array}\right\}\right) \\
& -\phi\left(\max \left\{d\left(y_{2 n+2}, y_{2 n+1}\right), D\left(f x_{2 n+2}, S x_{2 n+2}\right), D\left(f x_{2 n+1}, T x_{2 n+1}\right)\right\}\right) .
\end{aligned}
$$

Since $\frac{1}{2}\left[d\left(y_{2 n+1}, y_{2 n+3}\right)\right] \leq \max \left\{d\left(y_{2 n+1}, y_{2 n+2}\right), d\left(y_{2 n+2}, y_{2 n+3}\right)\right\}$, it follows that

$$
\begin{aligned}
\psi\left(d\left(y_{2 n+2}, y_{2 n+3}\right)\right) \leq & \psi\left(\max \left\{d\left(y_{2 n+1}, y_{2 n+2}\right), d\left(y_{2 n+2}, y_{2 n+3}\right)\right\}\right) \\
& -\phi\left(\max \left\{d\left(y_{2 n+1}, y_{2 n+2}\right), D\left(f x_{2 n+2}, S x_{2 n+2}\right), D\left(f x_{2 n+1}, T x_{2 n+1}\right)\right\}\right) .
\end{aligned}
$$


Suppose that $d\left(y_{2 n+1}, y_{2 n+2}\right) \leq d\left(y_{2 n+2}, y_{2 n+3}\right)$ and $d\left(y_{2 n+1}, y_{2 n+2}\right) \leq D\left(f x_{2 n+2}, S x_{2 n+2}\right)$, for some positive integer $n$.

Then from (7), we have

$\psi\left(d\left(y_{2 n+2}, y_{2 n+3}\right)\right) \leq \psi\left(d\left(y_{2 n+2}, y_{2 n+3}\right)\right)-\phi\left(D\left(f x_{2 n+2}, S x_{2 n+2}\right)\right)$,

that is,$\phi\left(D\left(f x_{2 n+2}, S x_{2 n+2}\right)\right) \leq 0$ which implies that $D\left(f x_{2 n+2}, S x_{2 n+2}\right)=0$, that is $f x_{2 n+2} \in S x_{2 n+2}$ or $y_{2 n+2} \in S x_{2 n+2}$ contradicting the formation of the sequence. Therefore $D\left(f x_{2 n+2}, S x_{2 n+2}\right)<d\left(y_{2 n+1}, y_{2 n+2}\right)$, for all $n \geq 0$. Again suppose that $d\left(y_{2 n+1}, y_{2 n+2}\right) \leq d\left(y_{2 n+2}, y_{2 n+3}\right)$ and $d\left(y_{2 n+1}, y_{2 n+2}\right) \leq D\left(f x_{2 n+1}, T x_{2 n+1}\right)$, for some positive integer $n$. Then from (7), we have

$\psi\left(d\left(y_{2 n+2}, y_{2 n+3}\right)\right) \leq \psi\left(d\left(y_{2 n+2}, y_{2 n+3}\right)\right)-\phi\left(D\left(f x_{2 n+1}, T x_{2 n+1}\right)\right)$,

that is, $\phi\left(D\left(f x_{2 n+1}, T x_{2 n+1}\right)\right) \leq 0$, which implies that $D\left(f x_{2 n+1}, T x_{2 n+1}\right)=0$, that is $f x_{2 n+1} \in T x_{2 n+1}$ or $y_{2 n+1} \in T x_{2 n+1}$ contradicting the formation of the sequence.

Therefore $D\left(f x_{2 n+1}, T x_{2 n+1}\right)<d\left(y_{2 n+1}, y_{2 n+2}\right)$, for all $n \geq 0$.

Thus $\left\{d\left(y_{n}, y_{n+1}\right)\right\}$ is a monotone decreasing sequence of non-negative real numbers.

Hence there exists an $r \geq 0$ such that

$\lim _{n \rightarrow \infty} d\left(y_{n}, y_{n+1}\right)=r$.

In view of (6), for all $n \geq 0$,

$\psi\left(d\left(y_{2 n+1}, y_{2 n+2}\right)\right) \leq \psi\left(d\left(y_{2 n}, y_{2 n+1}\right)\right)-\phi\left(d\left(y_{2 n}, y_{2 n+1}\right)\right)$.

Taking the limit as $n \rightarrow \infty$ in the above inequality and using the continuity of $\phi$ and $\psi$, we have

$\psi(r) \leq \psi(r)-\phi(r)$,

which is a contradiction unless $r=0$.

Hence we have

$\lim _{n \rightarrow \infty} d\left(y_{n}, y_{n+1}\right)=0$.

Now we shall show that $\left\{y_{n}\right\}$ is a Cauchy sequence. It is sufficient to show that $\left\{y_{2 n}\right\}$ is a Cauchy sequence. Suppose that $\left\{y_{2 n}\right\}$ is not a Cauchy sequence. Then there exists an $\epsilon>0$ such that for each integer $2(k)$ there exists an even integer,

$2 m(k)>2 n(k)>2(k)$

such that

$d\left(y_{2 n(k)}, y_{2 m(k)}\right) \geq \epsilon$,

for every integer $2(k)$. Let $2 m(k)$ be the least even integer exceeding $2 n(k)$ satisfying (10), such that

$d\left(y_{2 n(k)}, y_{2 m(k)-2}\right)<\epsilon$.

Using the triangle inequality, we have

$\epsilon \leq d\left(y_{2 n(k)}, y_{2 m(k)}\right) \leq d\left(y_{2 n(k)}, y_{2 m(k)-2}\right)+d\left(y_{2 m(k)-2}, y_{2 m(k)-1}\right)+d\left(y_{2 m(k)-1}, y_{2 m(k)}\right)$,

that is,

$\epsilon \leq d\left(y_{2 n(k)}, y_{2 m(k)}\right)<\epsilon+d\left(y_{2 m(k)-2}, y_{2 m(k)-1}\right)+d\left(y_{2 m(k)-1}, y_{2 m(k)}\right)$.

Letting $k \rightarrow \infty$ in the above inequality and using (9), we have

$\lim _{k \rightarrow \infty} d\left(y_{2 n(k)}, y_{2 m(k)}\right)=\epsilon$.

Again

$d\left(y_{2 n(k)}, y_{2 m(k)}\right) \leq d\left(y_{2 n(k)}, y_{2 n(k)+1}\right)+d\left(y_{2 n(k)+1}, y_{2 m(k)+1}\right)+d\left(y_{2 m(k)+1}, y_{2 m(k)}\right)$

and

$d\left(y_{2 n(k)+1}, y_{2 m(k)+1}\right) \leq d\left(y_{2 n(k)+1}, y_{2 n(k)}\right)+d\left(y_{2 n(k)}, y_{2 m(k)}\right)+d\left(y_{2 m(k)}, y_{2 m(k)+1}\right)$. 
Letting $k \rightarrow \infty$ in the above inequality and using (9) and (11), we have

$\lim _{k \rightarrow \infty} d\left(y_{2 n(k)+1}, y_{2 m(k)+1}\right)=\epsilon$.

Again

$d\left(y_{2 n(k)}, y_{2 m(k)+2}\right) \leq d\left(y_{2 n(k)}, y_{2 n(k)+1}\right)+d\left(y_{2 n(k)+1}, y_{2 m(k)+1}\right)+d\left(y_{2 m(k)+1}, y_{2 m(k)+2}\right)$.

Letting $k \rightarrow \infty$ in the above inequality and using (9) and (12), we have

$\lim _{k \rightarrow \infty} d\left(y_{2 n(k)}, y_{2 m(k)+2}\right)=\epsilon$.

Further

$d\left(y_{2 n(k)}, y_{2 m(k)+1}\right) \leq d\left(y_{2 n(k)}, y_{2 n(k)+1}\right)+d\left(y_{2 n(k)+1}, y_{2 m(k)+1}\right)$.

Letting $k \rightarrow \infty$ in the above inequality and using (9) and (12), we have

$\lim _{k \rightarrow \infty} d\left(y_{2 n(k)}, y_{2 m(k)+1}\right)=\epsilon$.

Putting $x=y_{2 n(k)}$ and $y=y_{2 m(k)+1}$ in (3), we have

$$
\begin{aligned}
& \psi\left(d\left(y_{2 n(k)+1}, y_{2 m(k)+2}\right)\right) \leq \psi\left(H\left(S x_{2 n(k)}, T x_{2 m(k)+1}\right)\right) \leq \psi\left(M\left(x_{2 n(k)}, x_{2 m(k)+1}\right)\right)-\phi\left(m\left(x_{2 n(k)}, x_{2 m(k)+1}\right)\right) \\
& \leq \psi\left(\max \left\{\begin{array}{c}
d\left(f x_{2 n(k)}, f x_{2 m(k)+1}\right), D\left(f x_{2 n(k)}, S x_{2 n(k)}\right), D\left(f x_{2 m(k)+1}, T x_{2 m(k)+1}\right), \\
\frac{1}{2}\left[D\left(f x_{2 n(k)}, T x_{2 m(k)+1}\right)+D\left(f x_{2 m(k)+1}, S x_{2 n(k)}\right)\right]
\end{array}\right\}\right) \\
& -\phi\left(\max \left\{d\left(f x_{2 n(k)}, f x_{2 m(k)+1}\right), D\left(f x_{2 n(k)}, S x_{2 n(k)}\right), D\left(f x_{2 m(k)+1}, T x_{2 m(k)+1}\right)\right\}\right) \\
& \leq \psi\left(\max \left\{\begin{array}{c}
d\left(y_{2 n(k)}, y_{2 m(k)+1}\right), d\left(y_{2 n(k)}, y_{2 n(k)+1}\right), d\left(y_{2 m(k)+1}, y_{2 m(k)+2}\right), \\
\frac{1}{2}\left[d\left(y_{2 n(k)}, y_{2 m(k)+2}\right)+d\left(y_{2 m(k)+1}, y_{2 n(k)+1}\right)\right]
\end{array}\right\}\right) \\
& -\phi\left(\max \left\{d\left(y_{2 n(k)}, y_{2 m(k)+1}\right), d\left(y_{2 n(k)}, y_{2 n(k)+1}\right), d\left(y_{2 m(k)+1}, y_{2 m(k)+2}\right)\right\}\right) \text {. }
\end{aligned}
$$

Letting $k \rightarrow \infty$ in the above inequality and using (9),(11-14) and using the continuity of $\phi$ and $\psi$, we have

$\psi(\epsilon) \leq \psi(\epsilon)-\phi(\epsilon)$

which is a contradiction by virtue of a property of $\phi$.

Therefore $\left\{y_{2 n}\right\}$ is a Cauchy sequence. In view of (9), $\left\{y_{n}\right\}$ is a Cauchy sequence in $X$.

Since $X$ is complete, then there exists a point $z$ in $X$ such that

$\lim _{n \rightarrow \infty} y_{2 n+1}=z=\lim _{n \rightarrow \infty} f x_{2 n+1} \in S x_{2 n}$

and

$\lim _{n \rightarrow \infty} y_{2 n+2}=z=\lim _{n \rightarrow \infty} f x_{2 n+2} \in T x_{2 n+1}$.

Since $f(X)$ is closed, then there exist a point $u$ in $X$ such that $f u=z$.

Now firstly we have

$$
\begin{aligned}
\psi\left(D\left(S u, f x_{2 n+2}\right)\right) \leq & \psi\left(H\left(S u, T x_{2 n+1}\right)\right) \\
\leq & \psi\left(M\left(u, x_{2 n+1}\right)\right)-\phi\left(m\left(u, x_{2 n+1}\right)\right) \\
\leq & \psi\left(\max \left\{\begin{array}{c}
d\left(f u, f x_{2 n+1}\right), D(f u, S u), D\left(f x_{2 n+1}, T x_{2 n+1}\right), \\
\frac{1}{2}\left[D\left(f u, T x_{2 n+1}\right)+D\left(f x_{2 n+1}, S u\right)\right]
\end{array}\right\}\right) \\
& -\phi\left(\max \left\{d\left(f u, f x_{2 n+1}\right), D(f u, S u), D\left(f x_{2 n+1}, T x_{2 n+1}\right)\right\}\right) .
\end{aligned}
$$

Taking limit $n \rightarrow \infty$, we have

$$
\begin{aligned}
\psi(D(S u, z)) \leq & \psi\left(\max \left\{d(z, z), D(z, S u), d(z, z), \frac{1}{2}[d(z, z)+D(z, S u)]\right\}\right) \\
& -\phi(\max \{d(z, z), D(z, S u), d(z, z)\}) \\
\leq & \psi\left(\max \left\{0, D(S u, z), 0, \frac{1}{2}[0+D(z, S u)]\right\}\right) \\
& -\phi(\max \{0, D(z, S u), 0\}) \\
\leq & \psi(D(S u, z))-\phi(D(S u, z)),
\end{aligned}
$$


which implies that $\phi(D(S u, z))=0$. Hence $D(S u, z)=0$, that is $z \in S u$.

Therefore $z=f u \in S u$.

Now if $f f u=f u$, then $f z=z$ and from the $(I T)$ - commutativity of $S$ and $f$, we have

$z=f z=f f u \in f S u \subset S f u=S z$,

implies $z=f z \in S z$.

Further

$$
\begin{aligned}
\psi\left(D\left(f x_{2 n+1}, T u\right)\right) \leq & \psi\left(H\left(S x_{2 n}, T u\right)\right) \\
\leq & \psi\left(M\left(x_{2 n}, u\right)\right)-\phi\left(m\left(x_{2 n}, u\right)\right) \\
\leq & \psi\left(\max \left\{\begin{array}{c}
d\left(f x_{2 n}, f u\right), D\left(f x_{2 n}, S x_{2 n}\right), D(f u, T u), \\
\frac{1}{2}\left[D\left(f x_{2 n}, T u\right)+D\left(f u, S x_{2 n}\right)\right]
\end{array}\right\}\right) \\
& -\phi\left(\max \left\{d\left(f x_{2 n}, f u\right), D\left(f x_{2 n}, S x_{2 n}\right), D(f u, T u)\right\}\right) .
\end{aligned}
$$

Taking limit $n \rightarrow \infty$, we have

$$
\begin{aligned}
\psi(D(z, T u)) \leq & \psi\left(\max \left\{d(z, z), d(z, z), D(z, T u), \frac{1}{2}[D(z, T u)+d(z, z)]\right\}\right) \\
& -\phi(\max \{d(z, z), d(z, z), D(z, T u)\}) \\
\leq & \psi\left(\max \left\{0,0, D(z, T u), \frac{1}{2}[D(z, T u)+0]\right\}\right) \\
& -\phi(\max \{0,0, D(z, T u)\}) \\
\leq & \psi(D(z, T u))-\phi(D(z, T u)),
\end{aligned}
$$

which implies that $\phi(D(z, T u))=0$. Hence $D(z, T u)=0$, that is $z \in T u$.

Therefore $z=f u \in T u$.

Now if $f f u=f u$, then $f z=z$ and from the (IT)-commutativity of $T$ and $f$, we have

$z=f z=f f u \in f T u \subset T f u=T z$,

implies $z=f z \in T z$.

Thus $z$ is a common fixed point of $S, T$ and $f$.

Corollary 3.2. Let $(X, d)$ be a complete metric space. Let $S, T: X \rightarrow C(X)$ be two multi-valued mappings and $f: X \rightarrow X$ be a self-mapping such that for all $x, y \in X$

$S(X) \cup T(X) \subset f(X)$

$f(X)$ is closed

$\begin{aligned} H(S x, T y) \leq & \max \left\{d(f x, f y), D(f x, S x), D(f y, T y), \frac{1}{2}[D(f x, T y)+D(f y, S x)]\right\} \\ & -\phi(\max \{d(f x, f y), D(f x, S x), D(f y, T y)\}),\end{aligned}$

where $\phi:[0, \infty) \rightarrow[0, \infty)$ is a continuous function with $\phi(t)=0$ if and only if $t=0$. Then $S, f$ and $T, f$ have a coincidence point. Further, if $S$ and $f$ have a common fixed point $f u$ provided $f f u=f u$ and $S, f$ are (IT)-commuting at $u \in C(S, f)$ and if $T$ and $f$ have a common fixed point $f u$ provided $f f u=f u$ and $T, f$ are (IT)-commuting at $u \in C(T, f)$. Then $S, T$ and $f$ have a common fixed point.

Proof. By taking $\psi$ as an identity function in the proof of Theorem 3.1, we can get the proof.

Corollary 3.3. Let $(X, d)$ be a complete metric space. Let $S: X \rightarrow C(X)$ be a multi-valued mapping and $f: X \rightarrow X$ be a single-valued mapping such that for all $x, y \in X$

$S(X) \subset f(X)$

$f(X)$ is closed 


$$
\begin{aligned}
\psi(H(S x, S y)) \leq & \psi\left(\max \left\{d(f x, f y), D(f x, S x), D(f y, S y), \frac{1}{2}[D(f x, S y)+D(f y, S x)]\right\}\right) \\
& -\phi(\max \{d(f x, f y), D(f x, S x), D(f y, S y)\}),
\end{aligned}
$$

where $\phi:[0, \infty) \rightarrow[0, \infty)$ is a continuous function with $\phi(t)=0$ if and only if $t=0$ and $\psi:[0, \infty) \rightarrow[0, \infty)$ is an altering distance function. Then $S$ and $f$ have a coincidence point. Further, if $S$ and $f$ have a common fixed point $f u$ provided $f f u=f u$ and $S, f$ are $(I T)$-commuting at $u \in C(S, f)$. Then $S$ and $f$ have a common fixed point.

Proof. It may be completed following the proof of Theorem 3.1 by taking $S=T$.

Corollary 3.4. Let $(X, d)$ be a complete metric space. Let $S: X \rightarrow C(X)$ be a multi-valued mapping such that for all $x, y \in X$

$$
\begin{aligned}
\psi(H(S x, S y)) \leq & \psi\left(\max \left\{d(x, y), D(x, S x), D(y, S y), \frac{1}{2}[D(x, S y)+D(y, S x)]\right\}\right) \\
& -\phi(\max \{d(x, y), D(x, S x), D(y, S y)\}),
\end{aligned}
$$

where $\phi:[0, \infty) \rightarrow[0, \infty)$ is a continuous function with $\phi(t)=0$ if and only if $t=0$ and $\psi:[0, \infty) \rightarrow[0, \infty)$ is an altering distance function. Then $S$ has a unique fixed point.

Proof. If we take $S=T$ and $f$ as an identity mapping in Theorem 3.1, then we can get the proof. Now taking clue from Example 3.1 of [6] we have an example.

Example 3.5. Let $X=\{0,1,2,3, \ldots$.$\} . Let d: X \times X \rightarrow R$ be given as

$d(x, y)= \begin{cases}x+y, & \text { if } x \neq y \\ 0, & \text { if } x=y\end{cases}$

Then $(X, d)$ is a complete metric space.

Let $\psi:[0, \infty) \rightarrow[0, \infty)$ be defined as follows:

$\psi(t)=t^{2}$, for $\mathrm{t} \in[0, \infty)$.

Let $\phi:[0, \infty) \rightarrow[0, \infty)$ be defined as follows:

$\phi(s)=\left\{\begin{array}{ll}\frac{s^{2}}{2}, & \text { if } s \leq 1 \\ \frac{1}{2}, & \text { if } s>1\end{array} \quad\right.$ for $\quad s \in[0, \infty)$.

Then $\phi$ and $\psi$ have the properties mentioned in Theorem 3.1.

Let $S: X \rightarrow C(X)$ be defined as follows:

$S x= \begin{cases}\{x-1\}, & \text { if } x \neq 0 \\ \{0\}, & \text { if } x=0 .\end{cases}$

Sol. We can see that mapping $S$ is satisfying the contractive condition (21) but it is not satisfying the condition (6) of [8, Page 266].

Note. In the above example, we set $x=n+1$ and $y=n$, where $n$ is a positive integer.

Then according to the case $x \neq y$, if $y \neq 0$ and $x>y$,

$H(S x, S y)=2 n-1$,

and

$\max \left\{d(x, y), d(x, f x), d(y, f y), \frac{1}{2}[d(x, f y)+d(y, f x)]\right\}=2 n+1$.

Clearly

$H(S x, S y)=k_{n} \max \left\{d(x, y), d(x, f x), d(y, f y), \frac{1}{2}[d(x, f y)+d(y, f x)]\right\}$,

where

$k_{n}=\frac{2 n-1}{2 n+1}$. 
Since $k_{n} \rightarrow 1$ as $n \rightarrow \infty$, there dose not exist any $k$ with $0 \leq k<1$ such that

$$
H(S x, S y) \leq \operatorname{kmax}\left\{d(x, y), D(x, S x), D(y, S y), \frac{1}{2}[D(x, S y)+D(y, S x)]\right\},
$$

for each $x, y \in X$.

Hence Example 3.5 does not satisfy condition (6) of [8]. This show that condition (21) is more general than (6) of [8]. $[11]$.

Remark 3.6. In Corollary 3.4, we obtain slightly generalized version of Theorem 3.1 of [6] and Theorem 2.1 of

Remark 3.7. If we take $S$ and $T$ are single-valued mappings and $f$ as an identity mapping in Theorem 3.1, then we can get Theorem 3.2 of $[6]$.

Remark 3.8. As it is shown in [6] that a generalized weakly contractive condition 2.1 of [6] is more general than that (21) of Rhoades [27], so we can say that the contractive condition (3) and (17) are more general than the contractive condition used in [33].

\section{References}

[1] M.Abbas and D. Dorić,A common End point theorem for set-valued generalized $(\psi, \phi)$-weak contraction, Fixed Point Theory Appl. vol.2010, Article ID 509658,(2010), 1-8.

[2] M. Abbas and T. Nazir, Fixed point of generalized weakly contractive mappings in ordered partial metric spaces, Fixed Point Theory Appl. 2012 (2012), 1-19.

[3] Ya. I. Alber and S. Guerre-Delabriere, Principles of weakly contractive maps in Hilbert spaces, in: I. Goldberg, Yu. Lyubich , (eds.) New Results in Operator Theory, in: Advances and Appl. vol. 98, Birkhäuser, Basel, (1997), 7-22.

[4] M. Chandra, S. N. Mishra, S. L. Singh and B. E. Rhoades, Coincidences and fixed points of non-expansive type multivalued and single-valued maps, Indian J. Pure Appl. Math. 26(1995), no. 5, 393-401.

[5] T. H. Chang, Common fixed point theorems for multi-valued mappings, Math. Japon. 41 (1995), no. 2, 311-320.

[6] B. S. Choudhury, P. Konar, B. E. Rhoades, N. Metiya, Fixed point theorems for generalized weakly contractive mappings, Nonlinear Anal. 74 (2011), no. 6, 2116-2126.

[7] B. S. Choudhury and N. Metiya, Multi-valued and Single-valued fixed point results in partially ordered metric spaces, Arab J. Math. Sci. 17 (2011), 135-151.

[8] Lj. B. Ćirić, Fixed points for generalized multi-valued contractions, Mat. Vasnik, 9 (1972), no. 24, 265-272.

[9] B. Damjanović and D. Dorić, Multi-valued generalizations of the Kannan fixed point theorem, Filomat, 25 (2011), no. $1,125-131$.

[10] D. Delbosco, Un'estensione di un teorema sul puto fisso di. S. Reich, Rend. Sem. Mat. Univers. Torino, 35 (1976-77), 233-238.

[11] P. N. Dutta and B. S. Choudhury, A generalization of contraction principle in metric spaces, Fixed Point Theory Appl. vol. 2008 (2008), Article ID 406368, 1-8.

[12] U. C. Gairola, S. N. Mishra and S. L. Singh, Coincidence and fixed point theorems on product spaces, Demonstratio Math. 30 (1997), no. 1, 15-24.

[13] O. Hadžić and Lj. Gajić, Coincidence points for set-valued mappings in convex metric spaces, Univ.Novom Sadu Zb. Rad. Prirod-Mat. Fak. Ser. Mat. 16 (1986), 13-25.

[14] S. Itoh and W. Takahashi, Single-valued mappings, Multi-valued mappings and fixed point theorems, J. Math. Anal. Appl. 59 (1977), 514-521.

[15] G. Jungck, Common fixed points for non-continuous non-self maps on non-metris spaces, Far East J. Math. Sci. 4 (1996), 199-215.

[16] G. Jungck and B. E. Rhoades, Fixed point for set-valued functions without continuity, Indian J. Pure Appl. Math. 29 (1998), no. 3, 227-238. 
[17] H. Kaneko and S. Sessa, Fixed point theorems for compatible multi-valued and single-valued mappings, Internat. J. Math. Math. Sci. 12 (1989), no. 2, 257-262.

[18] M. S. Khan, Common fixed point theorems for multi-valued mappings, Pacific J. Math. 95 (1981), no. 2, 337-347.

[19] M.S. Khan, M. Swaleh and S. Sessa, Fixed point theorems by altering distances between the points, Bull. Austral. Math. Soc. 30 (1984), 1-9.

[20] A. Latif, A fixed point results for multi-valued generalized contraction maps, Filomat, 26 (2012), no. 5, $929-933$.

[21] Y. Liu, J. Wu and Z. Li, Common fixed points of single-valued and multi-valued maps, Internat. J. Math. Math. Sci. 19 (2005), 3045-3055.

[22] S. B. Nadler, Multi-valued contraction mappings, Pacfic J. Math. 30 (1969), no. 2, 475-487.

[23] R. P. Pant, Common fixed point theorems for contractive maps, J. Math. Anal. Appl. 226 (1998), $251-258$.

[24] H. K. Pathak, S. M. Kang and Y. J. Cho, Coincidence and fixed point theorems for non-linear hybrid generalized contractions, Czechoslovak Math. J. 48 (1998), no. 123, 341-357.

[25] O. Popescu, Fixed points for ( $\psi, \phi)$-weak contractions, Appl. Math. Lett. 24 (2011), 1-4.

[26] B. E. Rhoades, Some theorems on weakly contractive maps, Nonlinear Anal. 47 (2001), 2683-2693.

[27] B. E. Rhoades, A comprasion of various definitions of contractive mappings, Trans. Amer. Math. Soc. 226 (1977), 257-290.

[28] S. Sessa and B. Fisher, On common fixed points of weakly commuting mappings and set-valued mappings, Internat. J. Math. Math. Sci. 9 (1986),no. 2, 323-329.

[29] S. L. Singh and C. Kulshrestha, Coincidence theorems in metric spaces, Indian J. Phy. Natur. Sci. 2 (1982), 19-22.

[30] S. L. Singh and S. N. Mishra, Coincidences and fixed points of non-self hybrid contractions, J. Math. Anal. Appl. 256 (2001), 486-497.

[31] S. L. Singh and S. N. Mishra, Fixed point theorems for single-valued and multi-valued maps, Nonlinear Anal. 74 (2011), no. $6,2243-2248$.

[32] S. L. Singh, S. N. Mishra, R. Chugh and R. Kamal, General common fixed point theorems and applications, J. Appl. Math. vol.(2012), Article ID 902312, 1-14.

[33] S. L. Singh, K. S. Ha and Y. J. Cho, Coincidence and fixed points of nonlinear hybrid contractions, Internat. J. Math. Math. Sci. 12 (1989), no. 2, 247-256.

[34] A. Singh, R. C. Dimri and U. C. Gairola, A fixed point theorem for near-hybrid contraction, J. Nat. Acad. Math. 22 (2008), 11-22.

[35] F. Skof, Teorma di punti fisso per applicazioni negli spazi metrici, Atti. Acad. Sci. Torino, 111 (1977), 323-329. 